\title{
Staged ventricular recruitment in patients with borderline ventricles and large ventricular septal defects
}

\author{
Olubunmi O. Oladunjoye, MBBS, MPH, ${ }^{\mathrm{a}}$ Breanna Piekarski, RN, BSN, ${ }^{\mathrm{a}}$ Puja Banka, MD, ${ }^{\mathrm{b}}$ \\ Gerald Marx, MD, ${ }^{\mathrm{b}}$ Roger E. Breitbart, MD, ${ }^{\mathrm{b}}$ Pedro J. del Nido, MD, ${ }^{\mathrm{a}}$ and Sitaram M. Emani, MD ${ }^{\mathrm{a}}$
}

\section{ABSTRACT}

Objectives: Patients with borderline ventricles and ventricular septal defects (VSDs) who have previously undergone single ventricle palliation might be candidates for staged ventricular recruitment with the ultimate goal of biventricular conversion. This study aimed to determine the effect of atrial septal defect (ASD) restriction without VSD closure on ventricular growth in patients with borderline right or left ventricles and VSDs.

Methods: Patients with borderline ventricles and VSD who underwent a staged ventricular recruitment procedure with strategies to increase blood flow through hypoplastic ventricle via ASD restriction without VSD closure after single ventricle palliation were retrospectively reviewed. Pre- and postrecruitment ventricular volumes were compared using Wilcoxon signed rank test.

Results: A total of 21 patients underwent staged ventricular recruitment via ASD restriction without VSD closure at median age of 20.0 months (interquartile range [IQR], 8.0-52.5 months). At a median of 9.0 months (IQR, 8.0-11.8 months) after the recruitment procedure, there were increases in the median indexed ventricular diastolic volume $\left(31.7 \mathrm{~mL} / \mathrm{m}^{2}\right.$ [IQR, 24.5-37.1] to $48.5 \mathrm{~mL} / \mathrm{m}^{2}$ [IQR, 38.4-58.0; $P<.01])$, median indexed systolic volume $\left(13.3 \mathrm{~mL} / \mathrm{m}^{2}\right.$ [IQR, 9.7-18.7] to $19.5 \mathrm{~mL} / \mathrm{m}^{2}$ [IQR, 16.8-29.7]; $\left.P<.01\right)$, and the median indexed stroke volume (18.4 mL/m $\mathrm{m}^{2}$ [IQR, 14.8-21.1] to $28.1 \mathrm{~mL} / \mathrm{m}^{2}$ [IQR, 21.3-31.8]; $\left.P<.01\right)$. Biventricular conversion was ultimately performed in $14(67 \%)$. Two patients died after biventricular conversion.

Conclusions: Staged ventricular recruitment via ASD restriction without VSD closure is associated with growth of the hypoplastic ventricle. In patients who are deemed high-risk for single ventricle, this approach might facilitate eventual biventricular conversion. Further studies are needed to identify optimal candidates for this approach. (J Thorac Cardiovasc Surg 2018;156:254-64)

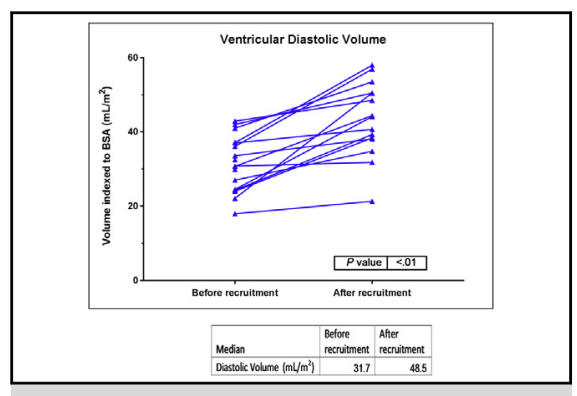

Pre- and postrecruitment volumes and mass.

\section{Central Message}

Restriction of atrial septal defect without ventricular septal defect closure is associated with an increase in ventricular volumes in patients with hypoplastic ventricle and large ventricular septal defect.

\section{Perspective}

Strategies that promote the growth of hypoplastic ventricles might allow patients with borderline ventricles to undergo biventricular conversion. An approach of staged ventricular recruitment with restriction of atrial septal defect without closure of ventricular septal defect resulted in growth of the hypoplastic ventricle and biventricular conversion in a subset of patients.

See Editorial Commentary page 265.
Patients with double outlet right ventricle (DORV) or unbalanced complete atrioventricular (AV) canal defect (uCAVC) and borderline right or left ventricular size might

\footnotetext{
From the Departments of ${ }^{\mathrm{a} C}$ ardiovascular Surgery, and ${ }^{\mathrm{b}}$ Pediatric Cardiology, Boston Children's Hospital, Boston, Mass.

This study was supported by funding from the Ethan Lindberg Foundation (Winnetka, Ill).

Read at the 97th Annual Meeting of The American Association for Thoracic Surgery, Boston, Massachusetts, April 29-May 3, 2017.

Received for publication April 29, 2017; revisions received Feb 20, 2018; accepted for publication March 1, 2018; available ahead of print April 27, 2018.

Address for reprints: Sitaram M. Emani, MD, Department of Cardiovascular Surgery, Boston Children's Hospital, 300 Longwood Ave, Boston, MA 02115 (E-mail: sitaram.emani@cardio.chboston.org).

0022-5223/\$36.00

Copyright (c) 2018 by The American Association for Thoracic Surgery

https://doi.org/10.1016/j.jtcvs.2018.03.111
}

undergo single ventricle palliation (SVP) because of concerns of ventricular hypoplasia. However, some patients, particularly those with risk factors for SVP, might be candidates for staged ventricular recruitment strategy in which procedures are performed to promote ventricular growth with the ultimate goal of biventricular (BIV) conversion. ${ }^{1-4}$ In previous experience with staged left ventricle (LV) recruitment strategy in patients with borderline

Scanning this QR code will take you to the supplemental videos. To view the AATS Annual Meeting Webcast, see the URL next to the webcast thumbnail. 


$$
\begin{aligned}
& \text { Abbreviations and Acronyms } \\
& \text { ASD }=\text { atrial septal defect } \\
& \text { AV }=\text { atrioventricular } \\
& \text { BDG }=\text { bidirectional Glenn } \\
& \text { BIV }=\text { biventricular } \\
& \text { BTS }=\text { Blalock-Taussig shunt } \\
& \text { CAVC }=\text { complete atrioventricular canal } \\
& \text { CMR }=\text { cardiac magnetic resonance } \\
& \text { DKS }=\text { Damus-Kaye-Stansel } \\
& \text { DORV }=\text { double outlet right ventricle } \\
& \text { EDV }=\text { end diastolic volume } \\
& \text { IQR }=\text { interquartile range } \\
& \text { LV }=\text { left ventricle } \\
& \text { PA }=\text { pulmonary artery } \\
& \text { PAB }=\text { pulmonary artery banding } \\
& \text { PBF }=\text { pulmonary blood flow } \\
& \text { RV }=\text { right ventricle } \\
& \text { SVP }=\text { single ventricle palliation } \\
& \text { uCAVC }=\text { unbalanced complete atrioventricular } \\
& \text { canal defect } \\
& \text { VSD }=\text { ventricular septal defect }
\end{aligned}
$$

hypoplastic left heart and intact ventricular septum, fenestrated atrial septal defect (ASD) closure was the technique most significantly associated with LV growth. ${ }^{1}$

However, because diastolic flow across a ventricular septal defect (VSD) limits the potential to volume load a hypoplastic ventricle, it was unclear whether a strategy of ASD restriction without VSD closure would promote ventricular growth in patients with an unrestrictive VSD. Although closure of the ASD as well as VSD ensures that all diastolic flow into the hypoplastic ventricle remains in that ventricle, such a strategy loads the unprepared ventricle with a full cardiac output and might lead to prohibitively elevated diastolic filling pressures and depressed systolic function. ${ }^{5}$ We hypothesized that ASD restriction without concurrent VSD closure would promote growth of the hypoplastic ventricle, and applied this staged ventricular recruitment strategy in a group of patients with DORV and uCAVC.

\section{METHODS \\ Study Design}

This was a single-center retrospective analysis of all patients who presented to Boston Children's Hospital between January 2009 and March 2016 with diagnosis of borderline left or right ventricle (RV) and VSD who had undergone ASD restriction while maintaining patency of the VSD as a strategy for recruitment of the borderline hypoplastic ventricle. The study was approved by the Boston Children's Hospital institutional review board. The hospital records were reviewed to collect demographic data, diagnosis, and details of surgical interventions before the ventricular recruitment procedure. Echocardiographic and cardiac magnetic resonance (CMR) imaging data were recorded before and after the recruitment procedures. The primary outcome measures were changes in volumes and mass of the hypoplastic ventricle after the ventricular recruitment procedure. Secondary outcomes included survival, rate of BIV conversion, and reoperation after BIV conversion.

\section{Inclusion Criteria}

Patients were included in the study if their cardiac anatomy included large VSD and ASD and borderline hypoplastic right or LV (end diastolic volume [EDV] z-score greater than -5 and less than -2 ), had undergone initial SVP (pulmonary artery [PA] banding [PAB], Norwood, DamusKaye-Stansel [DKS], or bidirectional Glenn [BDG]), and underwent subsequent ASD restriction with the intention of promoting ventricular growth (ventricular recruitment procedure). Patients were excluded if the ventricular septum was intact before ASD restriction or if the VSD was closed at the time of ASD restriction.

\section{Ventricular Recruitment Procedure}

The recruitment procedure was performed through a median sternotomy with cardiopulmonary bypass and moderate hypothermia $\left(28^{\circ} \mathrm{C}-32^{\circ} \mathrm{C}\right)$. The ASD was restricted with either glutaraldehyde-treated autologous pericardium or bovine pericardium. The degree of ASD restriction depended on adequacy of the hypoplastic AV valve. Complete closure was generally performed in patients who, after ASD restriction, had adequate size inflow (greater than $-2 \mathrm{z}$-score according to intraoperative sizing) into the hypoplastic ventricle through the ipsilateral $\mathrm{AV}$ valve. In patients with hypoplastic AV valve inflow (z-score $<-2)$ fenestrated ASD closure $(4 \mathrm{~mm}$ fenestration in center of the patch) was performed to avoid atrial hypertension ipsilateral to the hypoplastic AV valve and ventricle. In patients with complete atrioventricular septal defect, the superior and inferior bridging leaflets were approximated at the level of anticipated ASD restriction. The atrial patch was then sutured to the atrial aspect of the leaflets, leaving the VSD open beneath the leaflets. The patch was completed, and a fenestration was placed in the center of the ASD patch with a 4-mm aortic punch. In our experience, placement of the atrial patch allows for better coaptation of the superior and inferior bridging leaflets, and stabilizes the valve during the intermediate stage. Subsequent VSD repair was performed through the tricuspid valve for patients with isolated complete atrioventricular canal (CAVC) defect, or through the tricuspid valve and right ventricular infundibulum in patients with DORV/CAVC defect. In patients with DORV diagnosis alone, the VSD was closed through the right ventriculotomy performed for RV-PA conduit.

In a subset of patients with hypoplastic LV, pulmonary blood flow (PBF) was augmented by the addition of accessory Blalock-Taussig shunt (BTS) or upsizing of PAB so as to maximize pulmonary venous return and ventricular loading. Patients with hypoplastic LV in whom left atrial return was determined to be inadequate for left ventricular growth (older age at presentation or magnetic resonance imaging showing $<0.5$ ratio of pulmonary blood flow to systemic blood flow) were considered appropriate candidates for additional PBF.

\section{The BIV Conversion Procedure}

Decision to proceed to a BIV conversion was left to the discretion of the primary cardiologist and clinical care team. Staged recruitment with BIV conversion was generally recommended for patients with borderline left heart structures and risk factors for SVP including right ventricular dysfunction, valvular regurgitation, and pulmonary vascular disease. $\mathrm{Pa}-$ tients with right or left ventricular hypoplasia were considered candidates for BIV conversion when their hypoplastic ventricle achieved an EDV of $>30 \mathrm{~mL} / \mathrm{m}^{2}$, showed normal ventricular function, adequate AV valve size and function, and low end diastolic pressures on cardiac catheterization.

The BIV conversion procedure included takedown of 1 or more of the following: DKS, aortopulmonary shunts, cavopulmonary anastomoses, and PAB. Reconstruction involved baffling of the LV to aorta and 1 or more of the following: repair of CAVC defect, insertion of RV-PA conduit, 
and central PA plasty. Superior vena cava to right atrial continuity was established by anastomosis to the right atrial appendage with anterior augmentation with a hood of pericardium or polytetrafluroethylene. ${ }^{6}$

\section{Echocardiographic and CMR Data}

All patients received CMR or echocardiogram examinations before recruitment and within 24 months after the recruitment procedure. All CMR imaging was performed under general anesthesia. Ventricular volumes, flow measurements, and stroke volume obtained at CMR imaging were processed using commercially available software (QMass and QFlow, MEDIS Medical Imaging Systems, Leiden, The Netherlands). ${ }^{7-9}$ Ventricular mass, end diastolic and end systolic volumes, and stroke volumes were indexed to body surface area. Degree of AV valve regurgitation and left ventricular volumes and ejection fraction were abstracted from echocardiogram reports with the latter calculated using the $5 / 6 \times$ area $\times$ length method. ${ }^{7,10,11}$ Left ventricular volume and function parameters were from echocardiogram if data were not available in CMR images. Ventricular volumes and BSA abstracted from CMR imaging were used to calculate the z-scores for the diastolic volumes.

\section{Statistical Methods}

Analysis was done using IBM SPSS statistics version 23 software. $^{12}$ Categorical variables were reported as numbers and percentages whereas continuous variable were reported as median and interquartile range (IQR). Pre- and postrecruitment values were compared using Wilcoxon signed rank test. $P$ values $<.05$ were considered significant.

\section{RESULTS}

\section{Patient Characteristics}

Between January 2009 and March 2016, 21 patients with DORV, uCAVC, and borderline left or RV underwent a ventricular recruitment procedure as an intermediate stage to BIV conversion. There were 5 patients with hypoplastic $\mathrm{RV}$, whereas 16 patients had hypoplastic LV. The recruitment procedure was performed at a median age of 20.0 months (IQR, 8.0-52.5 months). Diagnosis included uCAVC alone in 11, DORV alone in 1, and DORV/uCAVC canal in 9 patients (Table1). Heterotaxy was present in 14 patients $(67 \%)$ and $5(24 \%)$ had dextrocardia. Eighteen patients $(86 \%)$ had initial palliative procedures. Procedures before recruitment (Table 2) included BDG in $11(52 \%)$, $\mathrm{PAB}$ in $7(33 \%)$, BTS in $8(38 \%)$, and stage 1 palliation in 1 patient. Patients had undergone a median of 2 procedures (IQR, 1-3) before the recruitment procedure with AV valve regurgitation graded as less than mild in $8(38 \%)$, mild in $8(38 \%)$, moderate in $4(19 \%)$, and severe in 1 $(5 \%)$ patient. Thirteen $(62 \%)$ patients had 1 or more risk factors for SVP including pulmonary vein stenosis, PA hypoplasia, AV valve regurgitation, or ventricular dysfunction.

\section{Surgical Procedure}

The restriction of ASD was performed with glutaraldehyde-treated autologous pericardium in $9(43 \%)$ and bovine pericardium in $12(57 \%)$. Common $\mathrm{AV}$ valve was partitioned in $19(90 \%)$ patients whereas $11(52 \%)$
TABLE 1. Patient characteristics $(\mathbf{N}=\mathbf{2 1})$

\begin{tabular}{|c|c|}
\hline Variable & Value \\
\hline $\begin{array}{l}\text { Age at ventricular recruitment } \\
\text { procedure, mo }\end{array}$ & 20.0 (IQR, 8.0-52.5) \\
\hline \multicolumn{2}{|l|}{ Sex, n $(\%)$} \\
\hline Male & $9(43)$ \\
\hline Female & $12(57)$ \\
\hline $\begin{array}{l}\text { Weight at ventricular recruitment } \\
\text { procedure, kilograms }\end{array}$ & 9.7 (IQR, 6.8-13.4) \\
\hline \multicolumn{2}{|l|}{ Diagnosis, $\mathrm{n}(\%)^{*}$} \\
\hline DORV alone & $1(5)$ \\
\hline CAVC defect alone & $11(52)$ \\
\hline CAVC and DORV & $9(43)$ \\
\hline Heterotaxy & $14(67)$ \\
\hline $\mathrm{T} 21$ & $3(14)$ \\
\hline Dextrocardia & $5(24)$ \\
\hline Coarctation & $4(19)$ \\
\hline TAPVR/PAPVR & $7(33)$ \\
\hline \multicolumn{2}{|l|}{ Hypoplastic ventricle, n (\%) } \\
\hline Left & $16(76)$ \\
\hline Right & $5(24)$ \\
\hline Ventricular diastolic volume, $\mathrm{mL} / \mathrm{m}^{2}$ & 31.7 (IQR, 24.5-37.1) \\
\hline LV EDV Z-score & $-3.56(\mathrm{IQR},-4.33$ to -3.27$)$ \\
\hline \multicolumn{2}{|l|}{ Recruitment procedures, $\mathrm{n}(\%) \dagger$} \\
\hline Fenestrated ASD & $15(71)$ \\
\hline $\begin{array}{l}\text { Partitioning of the common } \mathrm{AV} \\
\text { valve }\end{array}$ & $19(91)$ \\
\hline Additional AV valve procedures & $11(52)$ \\
\hline Additional VSD closure & $4(19)$ \\
\hline $\begin{array}{l}\text { Modification of pulmonary blood } \\
\text { flow }\end{array}$ & $17(81)$ \\
\hline Cross clamp time, minutes & $72.0(\mathrm{IQR}, 57.0-115.0)$ \\
\hline $\begin{array}{l}\text { Cardiopulmonary bypass time, } \\
\text { minutes }\end{array}$ & $154.0(\mathrm{IQR}, 122.5-175.5)$ \\
\hline \multicolumn{2}{|l|}{ Hospital course } \\
\hline ICU LOS, d & 6.0 (IQR, 4.0-20.5) \\
\hline Hospital LOS, d & $19.0(\mathrm{IQR}, 8.5-35.5)$ \\
\hline Mechanical ventilation duration, $\mathrm{d}$ & $3.0(\mathrm{IQR}, 1.5-6.0)$ \\
\hline \multicolumn{2}{|c|}{$\begin{array}{l}\text { IQR, Interquartile range; } D O R V \text {, double outlet right ventricle; } C A V C \text {, complete atrio- } \\
\text { ventricular canal; } T 2 I \text {, trisomy } 21 ; T A P V R \text {, total anomalous pulmonary venous re- } \\
\text { turn; } P A P V R \text {, partial anomalous pulmonary venous return; } L V E D V \text {, left ventricle } \\
\text { end diastolic volume; } A S D \text {, atrial septal defect; } A V \text {, atrioventricular; } V S D \text {, ventricular } \\
\text { septal defect; } I C U \text {, intensive care unit; } L O S \text {, length of stay. *One patient may have } \\
\text { more than } 1 \text { diagnosis. } \dagger \text { One patient may have more than } 1 \text { procedure. }\end{array}$} \\
\hline
\end{tabular}

had additional AV valve procedures including splitting of the papillary muscles in 4 , cleft closure in 8 , and annuloplasty or commissuroplasty in 5 patients. In 4 patients, additional muscular VSDs were closed, maintaining patency of the dominant membranous or conoventricular VSD. Modification of the PBF was achieved using PAB adjustment only in $2(10 \%)$, PAB band and shunt in $8(38 \%)$, BTS only in $2(10 \%)$, BDG in $2(10 \%)$, and RV-PA conduit in $3(14 \%)$. 
TABLE 2. Initial palliative procedures before recruitment procedure

\begin{tabular}{|c|c|}
\hline Patient & Initial palliative procedure(s) \\
\hline 1 & Coarctation repair, $\mathrm{PAB}$ \\
\hline 2 & $\mathrm{PAB}$, aortic arch repair, PDA ligation, DKS, BDG \\
\hline 3 & $\mathrm{PAB}$ \\
\hline 4 & PAB, aortic arch advancement, PDA ligation \\
\hline 5 & Arch repair, $\mathrm{PAB}$ \\
\hline 6 & BTS, BDG \\
\hline 7 & $\begin{array}{l}\text { RmBTS, PDA ligation, branch PA plasty, BDG, } \\
\text { attempted Fontan }\end{array}$ \\
\hline 8 & $\begin{array}{l}\text { LBTS; BDG, oversewing of pulmonary valve, MPA } \\
\text { ligation }\end{array}$ \\
\hline 9 & None \\
\hline 10 & None \\
\hline 11 & $\begin{array}{l}\text { Norwood, PDA division and ligation, Kawashima, } \\
\text { central branch PA patch augmentation, revision of } \\
\text { BDG connection with central PA patch plasty, } \\
\text { revision of Stansel connection with detachment of } \\
\text { MPA from descending aorta }\end{array}$ \\
\hline 12 & TAPVR repair, sutureless repair of LUPV \\
\hline 13 & PAB, TAPVR repair, left sided BDG \\
\hline 14 & BDG \\
\hline 15 & LmBTS, BDG, left PA plasty \\
\hline 16 & $\begin{array}{l}\text { BTS, Kawashima with division and oversewing of } \\
\text { main PA }\end{array}$ \\
\hline 17 & BDG \\
\hline 18 & None \\
\hline 19 & RmBTS, division of ductal ligament \\
\hline 20 & TAPVR repair, RPA unifocalization, RmBTS \\
\hline 21 & RBTS, PAB; BDG, PV oversewing, branch PA plasty \\
\hline
\end{tabular}

$P A B$, Pulmonary artery banding; $P D A$, patent ductus ligation; $D K S$, Daymus-KayeStansel; $B D G$, bidirectional Glenn; $B T S$, Blalock-Taussig shunt; $R m B T S$, right modified Blalock-Taussig shunt; $P A$, pulmonary artery; $L B T S$, left Blalock-Taussig shunt; $M P A$, main pulmonary artery; TAPVR, total anomalous pulmonary venous return; $L U P V$, left upper pulmonary vein; $L m B T S$, left modified Blalock-Taussig shunt; $R P A$, right pulmonary artery; $R B T S$, right Blalock Taussig shunt; $P V$, pulmonary vein.

Two patients required a second bypass run, 1 for repair of residual tricuspid and mitral valve regurgitation, and the other for addition of a modified BTS. Complications included postoperative bleeding in 1 patient. The median duration of intubation was 3.0 days (IQR, 1.5-6.0 days). The median postoperative intensive care unit length of stay was 6.0 days (IQR, 4.0-20.5 days), and median hospital length of stay was 19.0 days (IQR, 8.5-35.5 days).

\section{Patient Outcomes After the Recruitment Procedure}

Time between pre- and postrecruitment CMR examination was 9.7 months (IQR, 7.7-12.3 months). The median indexed ventricular diastolic volume increased from $31.7 \mathrm{~mL} / \mathrm{m}^{2}$ (IQR, 24.5-37.1 $\mathrm{mL} / \mathrm{m}^{2}$ ) prerecruitment

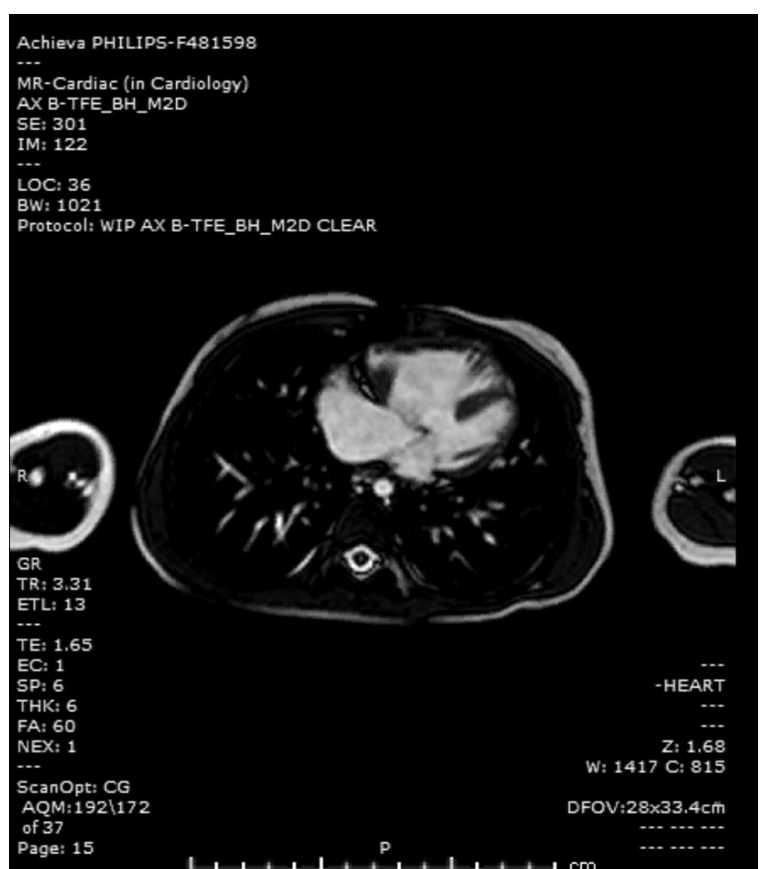

VIDEO 1. A patient's magnetic resonance imaging showing the left ventricle before recruitment. Video available at: https://www.jtcvs.org/ article/S0022-5223(18)30893-6/fulltext.

procedure to $48.5 \mathrm{~mL} / \mathrm{m}^{2}$ (IQR, 38.4-58.0 $\mathrm{mL} / \mathrm{m}^{2}$ ) postrecruitment $(P<.01)$ (Videos 1 and 2$)$. The median indexed systolic volume increased from $13.3 \mathrm{~mL} / \mathrm{m}^{2}$

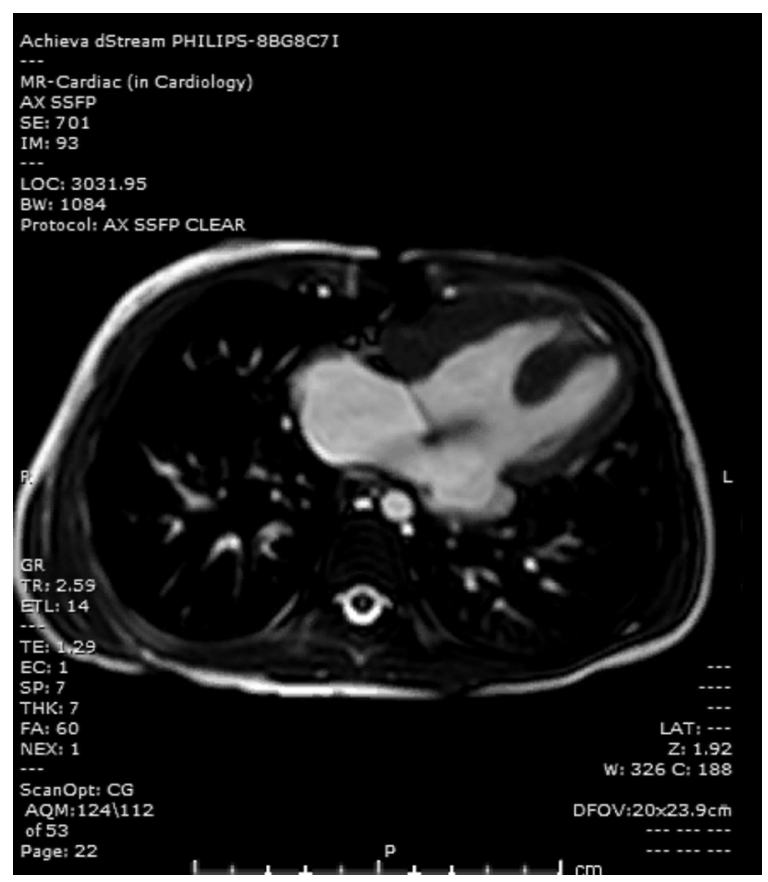

VIDEO 2. Magnetic resonance imaging showing left ventricle after recruitment. Video available at: https://www.jtcvs.org/article/S00225223(18)30893-6/fulltext. 

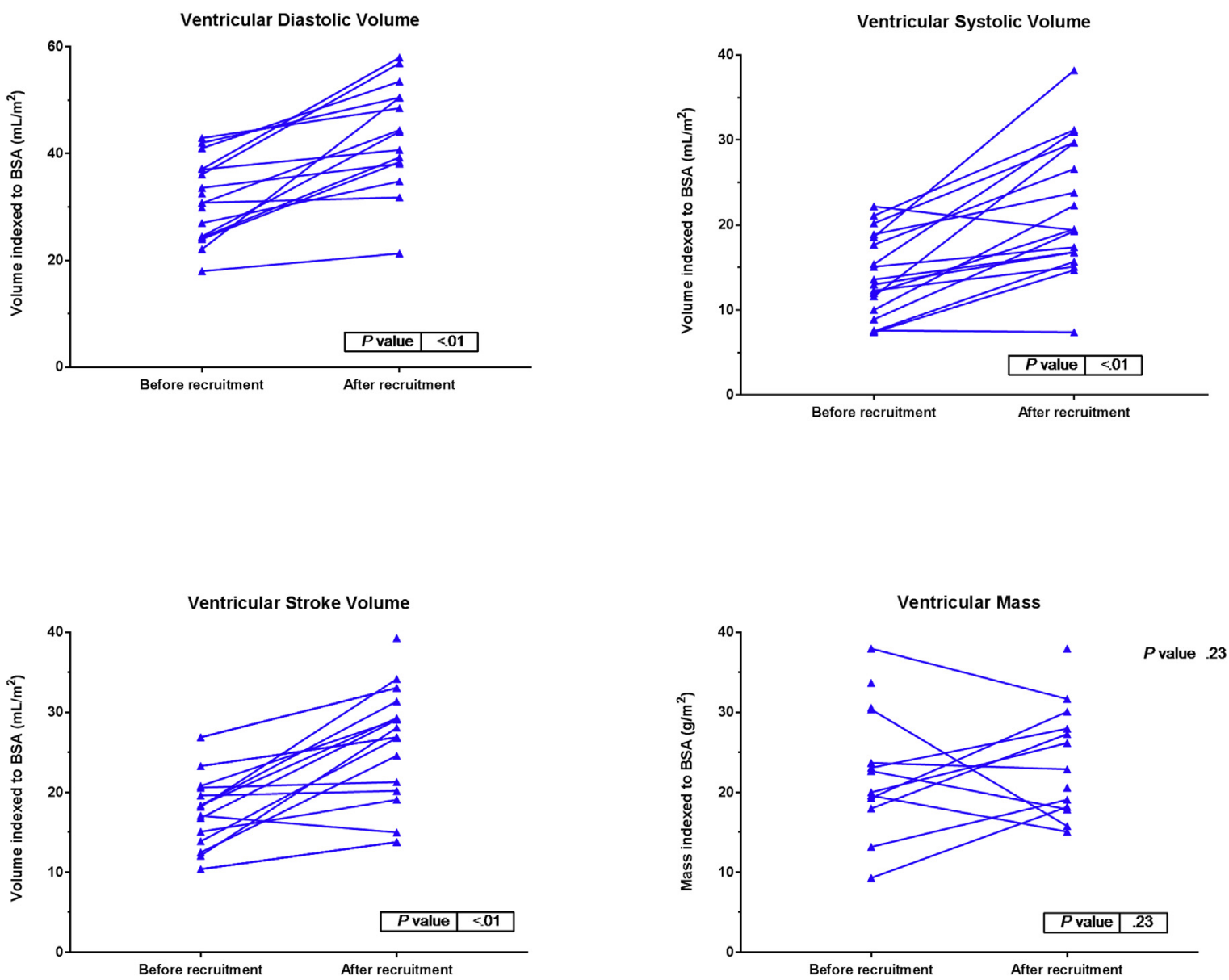

\begin{tabular}{|l|r|r|}
\hline Median & $\begin{array}{l}\text { Before } \\
\text { recruitment }\end{array}$ & $\begin{array}{l}\text { After } \\
\text { recruitment }\end{array}$ \\
\hline Diastolic Volume $\left(\mathrm{mL} / \mathrm{m}^{2}\right)$ & 31.7 & 48.5 \\
\hline Systolic Volume $\left(\mathrm{mL} / \mathrm{m}^{2}\right)$ & 13.3 & 19.5 \\
\hline Stroke Volume $\left(\mathrm{mL} / \mathrm{m}^{2}\right)$ & 18.4 & 28.1 \\
\hline Mass $\left(\mathrm{g} / \mathrm{m}^{2}\right)$ & 23.1 & 27.3 \\
\hline
\end{tabular}

FIGURE 1. Median ventricular volumes and mass before and after recruitment strategy via restriction of atrial septal defect without closure of ventricular septal defect. $B S A$, Body surface area.

(IQR, 9.7-18.7 $\mathrm{mL} / \mathrm{m}^{2}$ ) to $19.5 \mathrm{~mL} / \mathrm{m}^{2}$ (IQR, 16.8 $\left.29.7 \mathrm{~mL} / \mathrm{m}^{2} ; P<.01\right)$. The median indexed stroke volume increased from $18.4 \mathrm{~mL} / \mathrm{m}^{2}$ (IQR, $14.8-21.1 \mathrm{~mL} / \mathrm{m}^{2}$ ) to $28.1 \mathrm{~mL} / \mathrm{m}^{2}$ (IQR, 21.3-31.8 mL/m ${ }^{2} ; P<.01$ ). There was also an upward trend in the median indexed ventricular mass from $23.1 \mathrm{~g}$ (IQR, 19.3-33.7 g) to $27.3 \mathrm{~g}$ (IQR, 18.2-40.2 $\mathrm{g}$ ), but this difference was not statistically significant $(P=.21$; Figure 1$)$. The median EDV z-score of the hypoplastic LV before the recruitment procedure was -3.56 (IQR, -4.33 to -3.27 ) and after was -1.61 (IQR, -3.02 to $-0.37 ; P=.07)$. Only 1 patient had a distinct mitral valve orifice, and this had a mitral valve $\mathrm{z}$ score of -2.97 that increased to -0.54 after recruitment. The median ejection fraction of the hypoplastic ventricle was $56.8 \%$ (IQR, 51.1\%-61.5\%) before the recruitment and $55.8 \%(49.8 \%-57.9 \%)$ after the procedure $(P=.50)$. There was no difference in the growth of the ventricles $(P=.79)$ in a comparison of those with and without fenestration. Ventricular growth was observed in cohorts that did and did not receive additional PBF alike. Those who had a BTS had an increase in median EDV from 36.6 to $51.0 \mathrm{~mL} / \mathrm{m}^{2}$ and those without BTS had increase from 30.3 to $44.4 \mathrm{~mL} / \mathrm{m}^{2}$ but numbers were insufficient to perform statistical comparisons. The median left ventricular end diastolic pressure before recruitment was $10 \mathrm{~mm} \mathrm{Hg}$ and $11 \mathrm{~mm} \mathrm{Hg}$ after recruitment. 


\section{Time to BIV conversion}

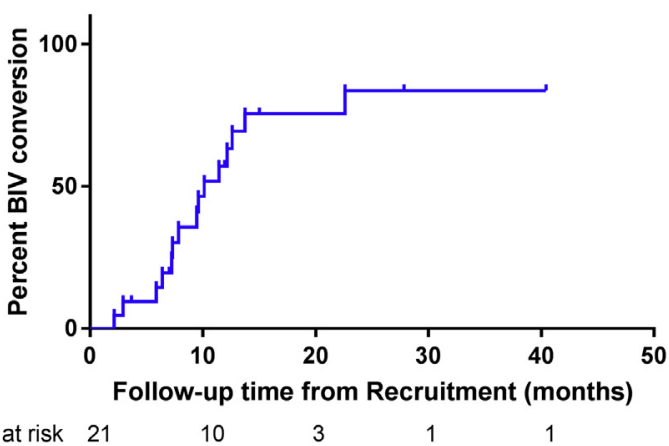

FIGURE 2. Kaplan-Meier curve for biventricular (BIV) conversion.

Of the 14 patients with AV regurgitation before recruitment, 7 had an improvement in the degree of regurgitation after surgery. One patient required reoperation within 7 days of recruitment operation for repair of the left $\mathrm{AV}$ valve with patch plasty of the superior bridging leaflet and posterior suture annuloplasty. The median follow-up time after recruitment was 15.5 months (IQR, 11.9-27.8 months). One patient died from complications of refractory ectopic atrial tachycardia 3 months after the recruitment procedure.

The BIV conversion procedure was performed in 14 of the 20 surviving patients. The median time to BIV conversion was 10 months after the recruitment procedure (Figure 2). The median age at BIV conversion was 24 months (IQR, 13.0-72.0 months). At BIV conversion, 7 patients had complete ASD closure and 13 had VSD closure without fenestration. Three patients had native pulmonary atresia, 3 had DKS, and 10 had oversewing of the main pulmonary artery or banding of the main pulmonary artery before BIV conversion. Nine of the 14 patients who had a BIV conversion required an RV-PA conduit. Median follow-up after BIV conversion was 9.9 months (IQR, 2.321.2 months), during which 3 patients underwent reoperation for repair/replacement of mitral regurgitation and 1 for repair of LV outflow obstruction.

Cardiac catheterization was performed on 7 of the 14 patients after BIV conversion. From the available data, the median ventricular end diastolic pressure after BIV conversion was $11 \mathrm{~mm} \mathrm{Hg}$, the median right to left ventricular systolic pressure ratio was 0.57 and the median transseptal gradient was $5 \mathrm{~mm} \mathrm{Hg}$. The mean left atrial pressures after mitral valve repair (as estimated by catheterization) in the patients who required mitral valve repair/replacement after BIV conversion were 8 and $14 \mathrm{~mm} \mathrm{Hg}$ (other 2 patients did not have left atrial pressures recorded). Five patients showed moderate/severe AV valve regurgitation and only 1 of these patients had moderate tricuspid regurgitation after the ASD restriction. Others had no, trivial, or mild regurgitation. After BIV conversion, however, 3 patients ultimately required reoperation for $\mathrm{AV}$ valve repair or replacement. Two patients died after BIV conversion, one from severe BIV dysfunction and the other from pulmonary hypertension. Of the remaining 6 patients without BIV conversion, 3 are still undergoing evaluation for anticipated BIV conversion, 1 has had the Fontan operation, and 2 are listed for heart transplantation. The 2 listed patients were deemed unsuitable for either BIV conversion or Fontan because of end-stage heart failure associated with moderate-severe BIV dysfunction. One of these patients also had poor growth the hypoplastic LV after the recruitment operation.

\section{DISCUSSION}

In this report we describe a technique for staged ventricular recruitment in patients with large VSD and borderline right or left ventricular size. Restriction of the ASD without closure of the VSD was associated with a significant increase in the size of the hypoplastic ventricle at a median of 9.7 months after recruitment. In a subset of such patients, BIV conversion was feasible. Long-term follow-up was not available to compare outcomes of BIV conversion with SVP in this cohort.

In patients with borderline left or RVs, the unpredictable outcomes and relative high risk of BIV repair have led many caregivers to pursue a single-ventricle pathway. ${ }^{13}$ Patients with heterotaxy syndrome and UCAVC or DORV historically have had high surgical mortality and worse long-term survival than other anatomic single-ventricle subtypes. ${ }^{14}$ The rationale behind the staged ventricular recruitment strategy is that gradual loading of the hypoplastic ventricle provides stimulus for ventricular remodeling. Patients who show adequate ventricular growth might then be considered candidates for BIV conversion, whereas patients with inadequate response might still undergo definitive SVP. In patients with risk factors for SVP, staged ventricular recruitment and BIV conversion might be an alternative to high-risk SVP or transplantation.

Staged ventricular recruitment with restriction of the ASD was associated with increase in the size of the hypoplastic right or LV in patients with uCAVC and DORV (Figures 1 and 3; Videos 1 and 2). We chose ASD restriction alone (without VSD closure) because this approach promotes flow across the hypoplastic AV valve and ventricle without restricting flow across left ventricular outflow tract or increasing risk of injury to the conduction system. Previous studies have shown that restriction of the ASD at the time of staged LV recruitment in patients with hypoplastic left heart syndrome variant is associated with LV growth and successful BIV repair. ${ }^{1,5}$ Growth of the ventricle was observed in patients with fenestrated ASD closure (performed if AV valve is significantly hypoplastic) as well as complete ASD closure without significant increase in left atrial pressure. Left ventricular growth seemed to occur in cohorts that did and did not receive additional 
Left ventricular Diastolic Volume

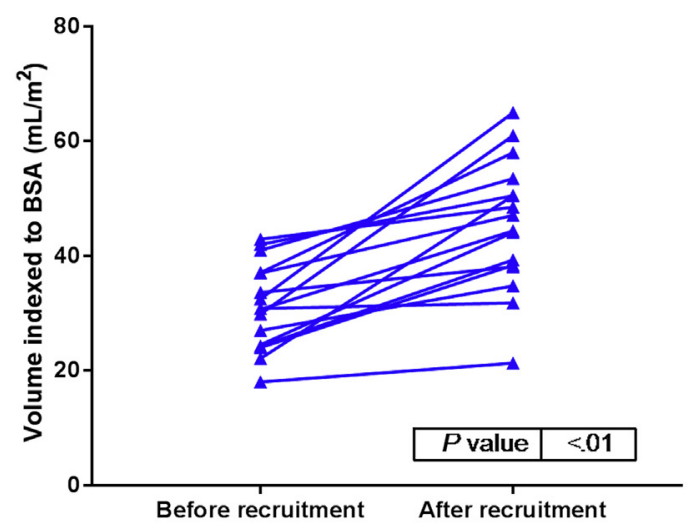

Left ventricular Stroke Volume

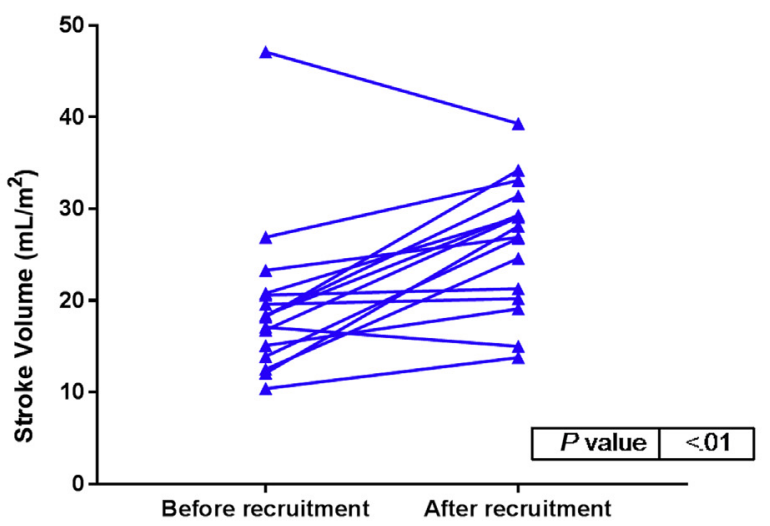

\section{Left Ventricular Systolic volume}

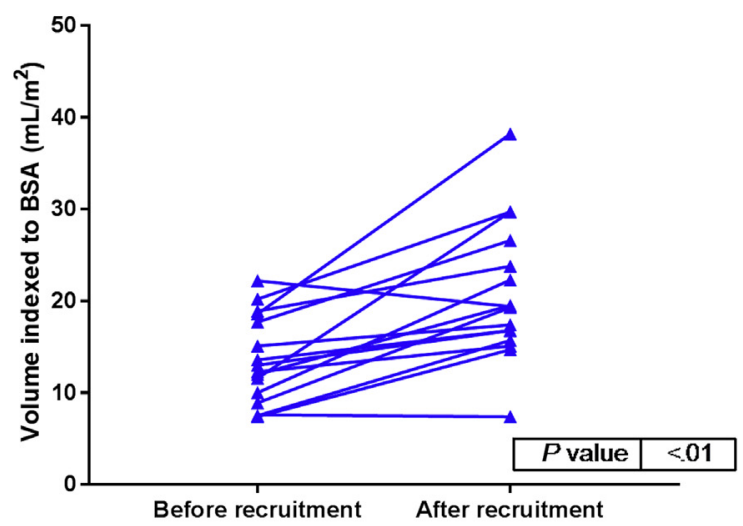

Left Ventricular Mass

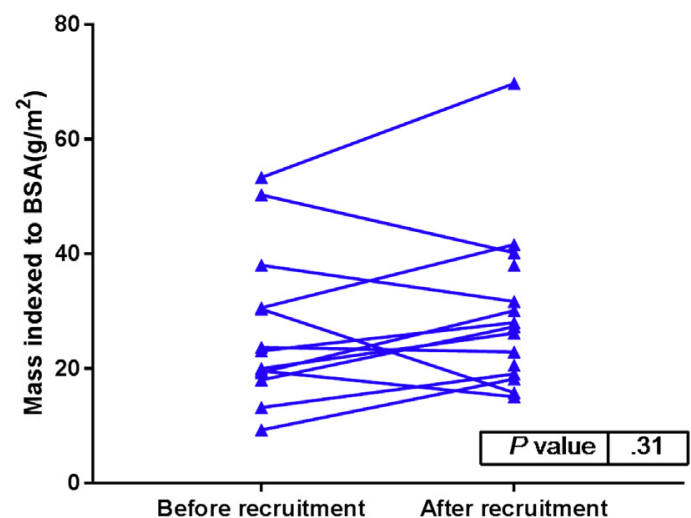

\begin{tabular}{|l|r|r|}
\hline Median & $\begin{array}{l}\text { Before } \\
\text { recruitment }\end{array}$ & $\begin{array}{l}\text { After } \\
\text { recruitment }\end{array}$ \\
\hline Diastolic Volume $\left(\mathrm{mL} / \mathrm{m}^{2}\right)$ & 30.8 & 44.2 \\
\hline Systolic Volume $\left(\mathrm{mL} / \mathrm{m}^{2}\right)$ & 12.7 & 19.4 \\
\hline Stroke Volume $\left(\mathrm{mL} / \mathrm{m}^{2}\right)$ & 18.3 & 27.5 \\
\hline Mass $\left(\mathrm{g} / \mathrm{m}^{2}\right)$ & 23.1 & 26.8 \\
\hline
\end{tabular}

FIGURE 3. Median left ventricular volumes and mass before and after recruitment strategy via restriction of atrial septal defect without closure of ventricular septal defect. BSA, Body surface area.

PBF alike. On the basis of this experience, our current practice is to perform fenestrated ASD closure with a 4mm central fenestration in patients with measured AV valve $\mathrm{Z}$-score less than -2 after ASD restriction. For patients who undergo recruitment for hypoplastic LV, an additional source of PBF is recommended in patients with ratio of pulmonary blood flow to systemic blood flow ratio of 0.5 or less.

The mechanisms underlying an increase in ventricular size were not determined in this study. Magnetic resonance imaging measurements performed in 1 patient showed that flow across the AV valve into the hypoplastic ventricle substantially increased after ASD restriction. ${ }^{1,7}$ Interestingly, end-diastolic pressure and left atrial pressure was not significantly higher after ASD restriction despite the increased flow. Several in vitro and animal studies have shown that cardiac remodeling adapts in response to changes in biomechanical stress or strain. ${ }^{15-17}$

An additional advantage of ASD restriction during the ventricular recruitment procedure in patients with uCAVC 
is the opportunity to address the common AV valve. The significant improvement in grade of regurgitation shown in this study is possibly related to stabilization of the inferior and superior bridging leaflets at the coaptation zone. In many patients with uCAVC, and especially in patients with heterotaxy, valvular regurgitation typically occurs at the central zone of coaptation between the superior and inferior bridging leaflets because of lack of adequate support. Placement of either VSD patch or atrial level patch prevents distraction in the lateral dimension of the common AV valve, and thus improves the zone of coaptation. The improvement in regurgitation benefits the patient in the interim while a decision regarding definitive SVP versus BIV conversion is assessed. Successful management of $\mathrm{AV}$ valve regurgitation is essential for long-term success of SVP, and thus an ancillary benefit of ASD restriction might be better long-term function of the AV valve in those palliated patients.

Alternative strategies to the ventricular recruitment procedure or SVP might be considered in certain patients with borderline ventricles. In patients with hypoplastic right heart structures, an alternative to SVP or BIV conversion is the " 1.5 ventricle" repair, in which a superior cavopulmonary shunt is augmented by right ventricular output consisting only of inferior vena cava venous return. Although the 1.5 ventricle circulation was not achieved in patients in this cohort, staged recruitment with the ultimate goal of 1.5 ventricle repair has been considered in patients with hypoplastic RVs. There are data to suggest that this approach has superior outcomes compared with SVP. ${ }^{18,19}$

There are several considerations in determining appropriate candidacy for staged ventricular recruitment. Many patients in this study were determined to have significant risk factors for SVP and potentially recruitable ventricles, therefore, staged ventricular recruitment was performed as an alternative to the Fontan procedure. In patients without risk factors for SVP, there are no data to suggest that BIV conversion provides any advantage over SVP. Also, the median age for ventricular recruitment in this study was 20 months; it is unclear if an association between ventricular recruit and growth would occur in older children or adults. The staged ventricular recruitment approach was not applied to patients with atresia of the AV valve, or to patients with extremely hypoplastic ventricles ( $Z$-score less than -5 ). Further studies are necessary to further refine selection criteria for the ventricular recruitment procedure.

Patients were generally considered candidates for BIV repair when the ventricular EDV reached $30 \mathrm{~mL} / \mathrm{m}^{2}$ and AV valve function was adequate. Although the rate of BIV conversion was $67 \%$ in our cohort, 3 of the patients are yet to be committed to either the BIV or SVP pathway and 1 patient did not show sufficient growth to permit BIV conversion. The rate of conversion and ventricular growth in this cohort was higher than that observed in patients with hypoplastic left heart syndrome variants.

This study has several important limitations in addition to those inherent in a retrospective analysis. Patients who underwent ventricular recruitment represented a clinically selected cohort with hypoplastic ventricles in whom ventricular growth might have occurred even in the absence of the ventricular recruitment procedure. A significant limitation of this study is the lack of a control cohort for comparison. In a cohort of patients with hypoplastic left heart syndrome and borderline LV, maintenance of unrestrictive ASD was associated with lack of growth of the LV over time compared with patients who underwent ASD restriction. ${ }^{1}$ Longitudinal data regarding size of the hypoplastic ventricle in patients with DORV and uCAVC after SVP are lacking. Prospective, randomized studies are necessary to definitively establish the effect of ASD restriction on ventricular growth and successful BIV conversion.

A contemporaneous, case-matched cohort was not available for comparison to determine the true effect of the procedure. This was a retrospective review and could not establish causation between restriction of ASD and ventricular growth. Also, BIV conversion might be associated with the increased risk of reoperation for conduit change and valvular surgery compared with patients who undergo SVP. Long-term follow-up after BIV conversion is not yet available, but these data will be important in determining the value of the ventricular recruitment procedure in this patient population.

\section{CONCLUSIONS}

Staged ventricular recruitment with restriction of the ASD without closure of the VSD is associated with growth of the borderline hypoplastic ventricle, and eventual BIV conversion in a subset of patients. Long-term follow-up with an appropriate control group is necessary to determine if the staged ventricular recruitment approach provides an advantage over SVP in patients with borderline ventricle.

\section{Webcast}

You can watch a Webcast of this AATS meeting presentation by going to: https://aats.blob.core.windows.net/ media/17AM/2017-05-03/RM306/05-03-17_Room306_ 0730_Oladunjoye.mp4.

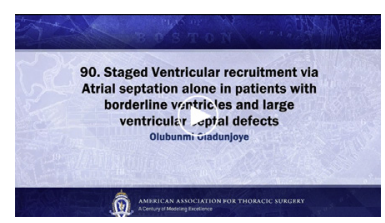

\section{Conflict of Interest Statement}

Authors have nothing to disclose with regard to commercial support. 


\section{References}

1. Emani SM, McElhinney DB, Tworetzky W, Myers PO, Schroeder B, Zurakowski D, et al. Staged left ventricular recruitment after single-ventricle palliation in patients with borderline left heart hypoplasia. J Am Coll Cardiol. 2012;60:1966-74.

2. Rhodes LA, Colan SD, Perry SB, Jonas RA, Sanders SP. Predictors of survival in neonates with critical aortic stenosis. Circulation. 1991;84:2325-35.

3. Schwartz ML, Gauvreau K, Geva T. Predictors of outcome of biventricular repair in infants with multiple left heart obstructive lesions. Circulation. 2001;104: 682-7.

4. Emani SM, Bacha EA, McElhinney DB, Marx GR, Tworetzky W, Pigula FA, et al. Primary left ventricular rehabilitation is effective in maintaining twoventricle physiology in the borderline left heart. J Thorac Cardiovasc Surg. 2009; 138:1276-82.

5. De Oliveira NC, Sittiwangkul R, McCrindle BW, Dipchand A, Yun TJ, Coles JG, et al. Biventricular repair in children with atrioventricular septal defects and a small right ventricle: anatomic and surgical considerations. J Thorac Cardiovasc Surg. 2005;130:250-7.

6. Baird CW, Myers PO, Borisuk M, Kalish B, Hofferberth S, Nathan M, et al. Takedown of cavopulmonary shunt at biventricular repair. J Thorac Cardiovasc Surg. 2014;148:1506-11.

7. Banka P, Schaetzle B, Komarlu R, Emani S, Geva T, Powell AJ. Cardiovascular magnetic resonance parameters associated with early transplantfree survival in children with small left hearts following conversion from a univentricular to biventricular circulation. J Cardiovasc Magn Reson. 2014;16:73.

8. Mooij CF, de Wit CJ, Graham DA, Powell AJ, Geva T. Reproducibility of MRI measurements of right ventricular size and function in patients with normal and dilated ventricles. J Magn Reson Imaging. 2008;28:67-73.

9. Buechel EV, Kaiser T, Jackson C, Schmitz A, Kellenberger CJ. Normal right-and left ventricular volumes and myocardial mass in children measured by steady state free precession cardiovascular magnetic resonance. J Cardiovasc Magn Reson. 2009; 11:19.

10. Lai WW, Geva T, Shirali GS, Frommelt PC, Humes RA, Brook MM, et al. Guidelines and standards for performance of a pediatric echocardiogram: a report from the Task Force of the Pediatric Council of the American Society of Echocardiography. J Am Soc Echocardiogr. 2006;19:1413-30.

11. Lopez L, Colan SD, Frommelt PC, Ensing GJ, Kendall K, Younoszai AK, et al. Recommendations for quantification methods during the performance of a pediatric echocardiogram: a report from the Pediatric Measurements Writing Group of the American Society of Echocardiography Pediatric and Congenital Heart Disease Council. J Am Soc Echocardiogr. 2010;23:465-95.

12. IBM. SPSS Statistics for Windows. Version 23. Armonk, NY: IBM Corp; 2014.

13. Hickey EJ, Caldarone CA, Blackstone EH, Lofland GK, Yeh T Jr, Pizarro C, et al. Critical left ventricular outflow tract obstruction: The disproportionate impact of biventricular repair in borderline cases. J Thorac Cardiovasc Surg. 2007;134: 1429-37.e1427.

14. Lim HG, Bacha EA, Marx GR, Marshall A, Fynn-Thompson F, Mayer JE, et al. Biventricular repair in patients with heterotaxy syndrome. J Thorac Cardiovasc Surg. 2009; 137:371-9.e373.

15. Russell B, Curtis MW, Koshman YE, Samarel AM. Mechanical stress-induced sarcomere assembly for cardiac muscle growth in length and width. J Mol Cell Cardiol. 2010;48:817-23.

16. Mansour H, de Tombe PP, Samarel AM, Russell B. Restoration of resting sarcomere length after uniaxial static strain is regulated by protein kinase $\mathrm{C} \varepsilon$ and focal adhesion kinase. Circ Res. 2004;94:642-9.

17. Taber LA. Biomechanical growth laws for muscle tissue. J Theor Biol. 1998;193: 201-13.

18. Chowdhury UK, Airan B, Sharma R, Bhan A, Kothari SS, Saxena A, et al. One and a half ventricle repair with pulsatile bidirectional Glenn: results and guidelines for patient selection. Ann Thorac Surg. 2001;71:1995-2002.

19. Kreutzer C, Mayorquim RC, Kreutzer GO, Conejeros W, Roman MI, Vazquez H, et al. Experience with one and a half ventricle repair. J Thorac Cardiovasc Surg. 1999;117:662-8.

Key Words: single ventricle, recruitment, biventricular conversion, unbalanced atrioventricular canal

\section{Discussion}

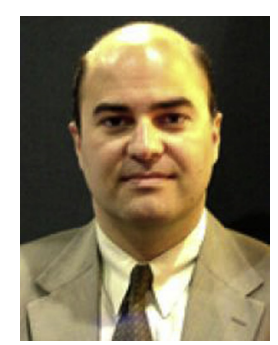

Dr Emile Bacha (New York, NY). I have no disclosures. Dr Oladunjoye, this was an excellent presentation. We as congenital heart surgeons often rehash the same topics and not much new often on those topics. This body of research is truly innovative and thought-provoking. Following it up on the proof of concept report that was published in JAAC in 2012 by Dr Emani done for borderline HLHS with intact ventricular septum, you have now successfully expanded this concept of atrial fenestration, essentially preloading or, I would call it, force loading the ventricles, and as you have shown pretty conclusively here, that can result in ventricular growth even in cases where the ventricular septum is left open. So this was physiologically not necessarily obvious, but I think you have shown that it can work.

So the main question is, what preoperative criteria would you use now that you have this experience to determine that this patient is going to be successful with a biventricular recruitment or not?

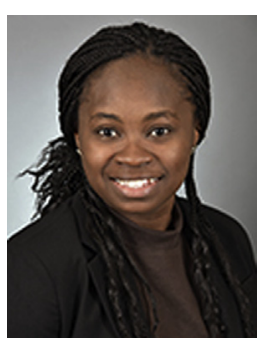

Dr Olubunmi O. Oladunjoye (Boston, Mass). Thank you for your question. Before now we used an enddiastolic volume of approximately $20 \mathrm{~mL} / \mathrm{m}^{2}$ to determine whether a patient should go and have a biventricular conversion or not, but over time we have realized that some might work and some might not, and hence the reason for this staged recruitment, to see if some of those with 20 would actually grow a little bit more. After this analysis, we did see that the minimum diastolic volume that achieved the biventricular conversion was approximately $34.8 \mathrm{~mL} / \mathrm{m}^{2}$.

Dr Bacha. And this is on the basis of MRI or echo?

Dr Oladunjoye. MRI.

Dr Bacha. Very interesting. A quick technical question. You do a 4-mm punch in the atrial septum, right, that is your technique?

Dr Oladunjoye. Yes.

Dr Bacha. Do you always leave it $4 \mathrm{~mm}$ irrespective of the size of the patient?

Dr Oladunjoye. No. There was a range to the fenestration. We had a median of 4 , but it ranged from 2 to $5 \mathrm{~mm}$.

Dr Bacha. Do you have a formula or you just say small patient $2 \mathrm{~mm}$, bigger patient $5 \mathrm{~mm}$ ?

Dr Oladunjoye. I would like to defer that question to $\mathrm{Dr}$ Emani. 


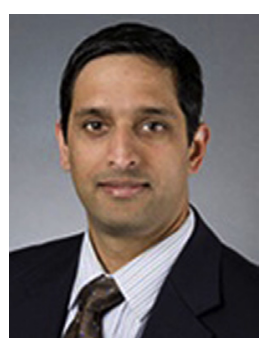

Dr Sitaram Emani (Boston, Mass). The idea is that we don't necessarily need to load the ventricle all at once. Our hypothesis is that even if you leave a relatively unrestrictive defect early on, it will constrict over time. So the decision regarding size of defect is really on the basis of the size of the mitral valve. Because the VSD is open, ventricular size per se does not factor into size of fenestration. If the mitral valve is especially small with $\mathrm{Z}$ score less than minus 3 , we will leave a slightly larger defect, because we don't want to risk atrial hypertension during the postoperative recovery phase. The defect will gradually self-restrict as the patient grows or scarring on the patch leads to gradual narrowing of the fenestration. However, if the mitral valve is of a nearly normal size and septation is performed for ventricular growth, then one might even septate the atrium without a fenestration.

Dr Bacha. And close the SD completely then?

Dr Emani. Correct.

Dr Bacha. The point here is that there is a lot of judgement involved in this decision-making. This is not an obvious decision to make whether to leave a fenestration. You are looking at the mitral valve orifice; you are looking at the LV or RV size depending on which one you are trying to grow. So if you could refine that decision-making process, that would be very, very helpful.

The other question I have is, $81 \%$ of your patients had some kind of a maneuver to increase pulmonary blood flow or modulate pulmonary blood flow. How do you decide that aspect of the procedure, because I was surprised; I didn't think you would have needed as many extra procedures.

Dr Emani. As you could imagine, many of these patients come to us already starting to get cyanotic. If they have a Glenn and they are nearly 2 years old, they are starting to get a little cyanotic, and so we need to increase the amount of pulmonary blood flow. In addition, we do not think that a QP:QS of 0.6 provides enough pulmonary venous return to stimulate left heart growth. We want to try to load the ventricle as best as we can. We are shifting toward increasing the amount of pulmonary blood flow by the addition of a shunt or by loosening the pulmonary artery band; that strategy has coincided with our experience with the "super Glenn" in patients who have single-ventricle physiology but need further rehabilitation of the left heart. We have drawn from that experience a little bit.

Dr Bacha. Can you explain the super Glenn?

Dr Emani. A super Glenn is a procedure in which we place or keep a Glenn to the right pulmonary artery, place a shunt into the central pulmonary artery to the left of the Glenn, and add a band or membrane between the two.
This allows augmentation of blood flow and allows nearly a full cardiac output then to go across the mitral valve and into the left ventricle, if it is the left ventricle you are trying to rehabilitate. Adding a shunt is not helpful in the setting of small right ventricle for obvious reasons.

Dr Bacha. Thank you. Again, the decision-making is a lot of intuition. It is not wrong but difficult for, let's say, the average pediatric heart surgeon.

A quick technical question. In AV canal, do you anchor the patch onto the AV valve or onto the atrial septal edge? It wasn't clear.

Dr Emani. For patients with a common AV valve, we will actually start the repair of the valve by suturing the pericardial patch in such a way as to bring the superior and inferior bridging leaflets together. We try to cheat a little bit toward the right side of the AV valve, essentially incorporating much of that leaflet into the left side of the heart. This allows us to redistribute the AV valve, which is a critical part of the repair of unbalanced AV canal defect. Partitioning the valve at this operation facilitates the VSD closure at the subsequent biventricular conversion procedure.

The approximation of the superior and inferior bridging leaflets also helps stabilize the AV valve in patients who have AV valve regurgitation. We have some data to show that the regurgitation actually gets better with this approach, making the circulation more stable during the interstage period.

Dr Bacha. A final thought. Again, the concept is extremely interesting and thought-provoking. Your survival at, I don't know, 3 years or 5 years is $80 \%$, so you are going to have to pit that against survival of a standard 3-stage single-ventricle repair for these patients who are often good candidates, not always; you might have patients with pulmonary hypertension in there that you are trying to rehabilitate. So the point is, this is what you are up against, but congratulations.

Dr Emani. Correct, we think this approach will be particularly useful in patients with risk factors for Fontan. Two of the mortalities had pulmonary vein stenosis and pulmonary hypertension and for that reason were not considered candidates for the Fontan. But we have also applied this strategy in patients without obvious risk factors.

Unidentified speaker. Thank you very much for your informative presentation about the hypoplastic ventricles. In our small experience after a Norwood procedure, and we had a short or a midterm follow-up, on checking the ventricle condition, some patients had higher left atrial pressure, more than 10 , and some were more than 15 , so midterm follow-up. Do you have any information about left atrial pressure or pulmonary venous hypertension or not?

Dr Oladunjoye. Could you repeat your question? 
Unidentified speaker. Do you have any follow-up data on left atrial pressure after these procedures?

Dr Emani. We monitor the left atrial pressure using echocardiogram and transatrial gradient. We have brought several patients back for catheterization. Some of them have come back for AV valve repair and had a catheterization at that time.

This population of patients, compared with hypoplastic left heart syndrome variants, actually adapt to volume loading quite well. So most have low end diastolic pressures and left atrial pressures, as long as they don't develop significant AV valve regurgitation or stenosis. The AV valve remains problematic in some patients, because a fair number of them have complex valvular disease at the time of biventricular repair.

Unidentified speaker. And at the closure of the ventricular septal defect, you leave their atrial fenestration or not?

Dr Emani. At the time of the complete repair, we will typically leave a small fenestration that will close over time, and we use the residual ASD to help monitor the atrial pressures.

Unidentified speaker. You measure the pressure gradients in the right and left atrium?

Dr Emani. That is correct.

Readers who found these articles interesting may also like to read the following papers found in recent and future issues of our sister publications, Seminars in Thoracic and Cardiovascular Surgery and Operative Techniques in Thoracic and Cardiovascular Surgery!

\section{Congenital: Single Ventricle}

ORIGINAL SUBMISSION: Targeted Increase in Pulmonary Blood Flow in a Bidirectional Glenn Circulation. Samuel L. Casella. Semin Thoracic Surg 2017: In press.

ORIGINAL SUBMISSION: Risk Factors for Gastrostomy Tube Placement in Single Ventricle Patients Following the Norwood Procedure. Kurt D. Piggott. Semin Thoracic Surg 2017: In press.

ORIGINAL SUBMISSION: Neurodevelopmental Outcome and Health Related Quality of Life in Children with Single Ventricle Heart Disease before Fontan Procedure. Bettina Reich. Semin Thoracic Surg 2017: 504-513.

Editorial Commentary: A Promise to Our Patients to Mind Neurodevelopment. Tara Karamlou. Semin Thoracic Surg 2017: 514-516. 